\title{
Rescue Ebola Patients in silico
}

Gang Zhao(1), Sebastian Binder(1), Georg Pongratz(2), Michael Meyer-Hermann(1,3)

1. Department of Systems Immunology and Braunschweig Integrated Centre of Systems Biology, Helmholtz Centre for Infection Research, Braunschweig, Germany

2. Department of Rheumatology, Hiller Research Center for Rheumatology, University Hospital Duesseldorf, Duesseldorf, Germany.

3. Institute of Biochemistry, Biotechnology and Bioinformatics, Technische Universität Braunschweig, Braunschweig, Germany

\section{Abstract}

Ebola, one of the most pathogenic and lethal viruses, repeatedly leads to severe outbreaks with large numbers of casualties. By integration of data of fatal, non-fatal and asymptomatic cases, we developed a mathematical model of the immune response to Ebola infections and found that TNF- $\alpha$ can explain subsequent cytokine responses and allows to quantitatively stratify patients into survivors and fatal cases. The model further suggests that antibodies provide the key resolving mechanism in survivors while IFN- $\gamma$ is the key defense mechanism in fatal cases. Exogenous IFN- $\gamma$ and inhibition of excessive inflammation have the potential to rescue fatal Ebola infections in silico. In view of the high mortality of this disease, limited real life studies, and the unforeseeable next outbreak, our in silico analysis is meant as a guide for future research by the determination of the most efficient strategies for Ebola treatment.

Ebola virus (EBOV) is a member of the Filoviridae family, a group of viruses highly pathogenic in humans and nonhuman primates. EBOV is subdivided into several species, with Zaire being the most lethal one. The case fatality rate of Zaire EBOV is $60 \%-90 \%$, and death usually occurs within 
5-7 days after symptom onset ${ }^{1,2}$. Fatal cases of Ebola virus disease (EVD) are characterized by uncontrolled virus replication, excessive release of inflammatory mediators by the host, lymphocyte apoptosis, coagulation abnormalities and organ damage ${ }^{3-5}$. The requirement of biosafety level 4 containment for the study of live virus strongly limits available data.

In vitro studies suggest that monocytes/macrophages and dendritic cells respond differently to EBOV infection. Monocytes/macrophages secrete a large amount of cytokines and chemokines upon infection in vitro. This is largely independent of virus replication as UV-treated virus particles elicited similar transcriptional activation and cytokine/chemokine secretion ${ }^{6}$. However, type 1 interferon production and response are inhibited by various EBOV proteins ${ }^{7-9}$. EBOV grows exponentially in primary human dendritic cells (DC); however, DC fail to secrete pro-inflammatory cytokines and their T cell stimulatory capacity is inhibited ${ }^{10,11}$. These results are in line with the notion that EBOV is able to cause global immunosuppression. Despite significant lymphocyte apoptosis, there is a rebound of the number of lymphocytes in a late-stage of EBOV infections in nonhuman primates ${ }^{12}$, mice ${ }^{13,14}$, and humans ${ }^{15}$ suggesting the activation of the adaptive immune response. Adoptive transfer studies showed that whole splenocytes from moribund EBOV infected mice protect naïve animals from EBOV challenge ${ }^{13}$. Specific antibody responses have also been observed in some EBOV and other filovirus infected fatal human cases ${ }^{16,17}$. These results suggest that although insufficient for control of the virus in the late phase, specific CD8+ T cell and B cell responses can be generated in fatal cases.

Patients surviving EBOV infection are characterized by early appearance of a pro-inflammatory response and an EBOV specific humoral response in blood, and EBOV specific cellular responses concomitant with virus clearance $e^{16,18,19}$. Fatal cases show late and uncontrolled pro-inflammatory 
cytokines in blood until death, with parallel very high levels of anti-inflammatory cytokines, which lead to a "cytokine storm" ${ }^{\prime 5,20}$ that is directly related to disease pathology ${ }^{12,21,22}$. EBOV infected asymptomatic humans are characterized by extraordinarily strong and rapidly resolved inflammatory responses followed by transient cytotoxic $\mathrm{T}$ cell activation and moderate IgG and $\operatorname{lgM}$ response ${ }^{3,23}$.

Taken together, current information supports the notion that the timing and the kinetics of viral replication and of the immune response is key to the outcome of infection and that by accelerating the immune response or retarding viral replication, the chance of survival might be substantially increased.

In view of limited experimental possibilities, mathematical models are important tools in understanding the race between viral replication and anti-viral immune responses. If validated by human patient data, such models could be used to stratify patients and to propose optimal treatment strategies. So far, only few mathematical modeling studies of EBOV infection exist in literature ${ }^{24,25}$; however, none of them aimed at explaining an in vivo human data set.

In this article, we developed a mathematical model for the cytokine response in EBOV infection, and parameterized the model by integration of different sets of human patient data for survivors, fatal cases ${ }^{18,20}$ and asymptomatic infections ${ }^{3,23}$. We tested different hypotheses for the reason of fate decisions when fitting the model to the data sets. The results suggested that a differential early inflammatory immune response to the virus can explain the whole history of the immune response of survivors, fatalities, and asymptomatic infection, while differential properties of the virus, or differential properties of the adaptive immune response, cannot explain the data. This model allows for a stratification of EBOV patients into survivors and fatal cases at the time of 
presentation in the clinics. Moreover, the model also suggested that fatal cases could be rescued by increasing and accelerating an effective T cell response and inhibiting excessive inflammation in a fine-tuned manner.

\section{Result}

\section{A model of cytokine response to Ebola infeciton}

A cytokine response model (Fig. 1) was developed and tailored to the availability of data on infection and immune response (see supplement for the details of the modelling approach). Here, we briefly introduce parameters that are important for understanding the following sections. The virus replicates with a rate $p$ and is removed by innate (represented by TNF- $\alpha$ ), by cellular (represented by IFN- $\gamma$ ), and by humoral immune responses (represented by antibodies) with a rate of $R_{\mathrm{f}}, R_{\mathrm{g}}$ and $R_{\mathrm{a}}$ respectively. TNF- $\alpha$ induction by virus and IFN- $\gamma$ is described by $Q_{\mathrm{vf}}$ and $Q_{\mathrm{gf}}$ respectively. IFN- $\gamma$ induction by virus, TNF- $\alpha$ and itself is described by $Q_{\mathrm{vg}}, Q_{\mathrm{fg}}$, and $Q_{\mathrm{gg}}$ respectively.

\section{The fate of the EBOV patient is derived from differential TNF- $\alpha$ responses}

With the aim to explore potential differences between EBOV fatalities, survivors, and asymptomatic infections in the inoculation phase, we carried out numerical optimization studies to test the following hypotheses:

H1) Initial viral dose and virus replication rate $(p)$ are different among the three groups;

$\mathrm{H} 2$ ) Virus clearance rate by the innate and the adaptive immune response $\left(R_{\mathrm{f}}\right.$ and $\left.R_{\mathrm{g}}\right)$ are different 
among the three groups;

$\mathrm{H} 3$ ) The innate immune responses $\left(Q_{\mathrm{vf}}\right.$ and $\left.Q_{\mathrm{gf}}\right)$ are different among the three groups;

$\mathrm{H} 4)$ The adaptive immune responses $\left(Q_{\mathrm{vg}}, Q_{\mathrm{fg}}\right.$ and $\left.Q_{\mathrm{gg}}\right)$ are different among the three groups.

$\mathrm{H} 5)$ Both the innate and the adaptive immune responses $\left(Q_{\mathrm{vf}}\right.$ and $\left.Q_{\mathrm{vg}}\right)$ are different among the three groups.

$\mathrm{H} 1, \mathrm{H} 2$ and $\mathrm{H} 4$ failed in explaining the data while $\mathrm{H} 3$ and $\mathrm{H} 5$ were compatible with the data. The best fit was obtained from H3 (Fig. 2, see also Fig. S1 for all the accepted fitting results from H3). The relative likelihood of the best result from H5 (Fig. S2, see also Fig. S3 for all the accepted fitting results) is 0.69 , meaning that $\mathrm{H} 5$ is 0.69 times as probable as $\mathrm{H} 3$ to simultaneously explain the three data sets. To make sure that the specific choice of the differential parameters does not influence the result, we also tested additional variations of the hypotheses (see Supplement), but none was compatible with the three data sets.

In order to find a fate decisive parameter, we analyzed the distributions of parameters in H3 (Fig. $3 \mathrm{~A}$ and $\mathrm{B}$ ), and $\mathrm{H} 5$ (Fig. $3 \mathrm{C}$ ). For both models ( $\mathrm{H} 3$ and $\mathrm{H} 5$ ), $Q_{v f}$, which represents TNF- $\alpha$ induction by EBOV, showed a sequence consistent with disease severity, with the asymptomatic infections being most and the fatalities being least sensitive to EBOV. In contrast, $Q_{\mathrm{gf}}$, which represents TNF- $\alpha$ induction by IFN- $\gamma$, of the three patient groups were comparable (in $\mathrm{H} 3, \mathrm{Fig} .3 \mathrm{~A}$ ), and $a_{\mathrm{F}}$ (in H3, Fig. 3B), which represents the maximal TNF- $\alpha$ production rate, was smallest in survivors and largest in asymptomatic infections. $Q_{v g}$, which represents IFN- $\gamma$ induction by EBOV, showed a similar pattern as $a_{\mathrm{F}}$ (in $\mathrm{H} 5$, Fig. $3 \mathrm{C}$ ). The values of other parameters are shown in the supplement Table 1 for both $\mathrm{H} 3$ and H5. We conclude that TNF- $\alpha$ induction by EBOV has the potential to be a fate decisive parameter. 
Since TNF- $\alpha$ response has been identified as the earliest difference that determined the final fate, we then asked whether a single measurement of TNF- $\alpha$ in the early phase could be used to predict the final outcome. We constructed five virtual patients whose TNF- $\alpha$ level on day 8 (the day of clinical admission) are 20,30,40, 50 and $60 \mathrm{pg} / \mathrm{ml}$, respectively. The mean TNF- $\alpha$ level of survivors and fatal cases on day 8 are 70 and $10 \mathrm{pg} / \mathrm{ml}$, respectively. We fitted the virtual patients, who have only one data point, together with the other three groups using hypothesis $\mathrm{H} 3$ (differential innate immune responses). The results suggested that a virtual patient mimics the fatalities, as quantified by the area under curve (AUC) of the viral load, if the TNF- $\alpha$ level on day 8 is $40 \mathrm{pg} / \mathrm{ml}$ or less and that a virtual patient could survive EBOV infection if his TNF- $\alpha$ on day 8 is $50 \mathrm{pg} / \mathrm{ml}$ or more (Fig. 4).

\section{Early immune response to EBOV suggested by the model}

The cytokine response after EBOV infection, as indicated by fitting results from both $\mathrm{H} 3$ and H5

(Fig. 2, S1 and S2), can be summarized as follows. For survivors, the TNF- $\alpha$ response was initiated early after infection. The level of TNF- $\alpha$ reached five times of its resting level between day 0 and 4. IFN- $\gamma$ either peaked on day 8 to more than five times the resting level $(\mathrm{H} 3, \mathrm{Fig}$. S1) or was downregulated after infection ( $\mathrm{H} 3$ and H5, Fig. S1 and S3). Interestingly, although we did not include IFN- $\gamma$ levels of survivors in the numerical study, a subset of the fitting results reproduced the reported values $\left(<20 \mathrm{pg} / \mathrm{ml} \mathrm{in}^{18}\right)$. However, we kept those fitting results that showed IFN- $\gamma$ upregulation in our analysis since IFN- $\gamma$ mRNA in circulating blood mononuclear cells from survivors showed such a trend ${ }^{18}$. Antibody levels exceeded a titer of 100 on day 7 and increased continuously afterwards. 
For fatal cases, IFN- $\gamma$ reached five times its resting level on day 7. TNF- $\alpha$ did this on day 11 . The antibody exceeded a titer of 100 on day 15 only, 1-2 days before death of the patients.

For asymptomatic cases, TNF- $\alpha$ reached fifty times the resting level on day 3 at the latest. IFN- $\gamma$ is either downregulated below resting level $(\mathrm{H} 3)$, or upregulated to around $100(\mathrm{H} 5)$ and $1000(\mathrm{H} 3)$ $\mathrm{pg} / \mathrm{ml}$. Antibody levels exceeded a titer of 100 around day 3.

Viral growth rate and viral clearance rates induced by different immune factors did not differ between the parameter sets of $\mathrm{H} 3$ (differential innate immune response) and $\mathrm{H} 5$ (differential innate and adaptive immune response) (Fig. 5), which supports the credibility of the results.

Interestingly, there was no difference between survivors and fatal cases before day 7 (Fig. 5). TNF- $\alpha$ induced viral clearance is negligible in both groups all along. For survivors (broken lines in Fig. 5), antibody-induced viral clearance was the main resolving mechanism, which appeared on day 7 and surpassed the viral growth rate on day 9. For the fatalities (full lines in Fig. 4), IFN- $\nu$-induced viral clearance increased from day 9 and constituted the main defense mechanism, although antibody also contributed a small part after day 13 , when the viral growth rate started to decrease. Although IFN- $\gamma$ is suggested to have nearly the same capacity in virus clearance as antibody (5.76e-6 vs 9.06e-6, and see the possible ranges in Table 1), IFN- $\gamma$ rose in the fatalities 2 days later than antibody did in the survivors (Fig. 5). We conclude that survivors and fatal cases differ in the timing of the immune response onset and in the choice of the dominant immune strategy.

\section{Immune-interfering therapy for Ebola patients}

Considering that both high viral load and excessive inflammations in fatal cases contribute to the 
multiple pathologies that finally led to death, we carried out simulations to explore the possibility of limiting viral replication and inflammation at the same time, by modulation of multiple aspects of the immune response. Fig. 6 shows the results of one example, in which exogenous IL-10 and IFN- $\gamma$ were added to fatal patients, with fixed doses, every 8 hours from day 8 , i.e. the first day after clinical admission. The simulation results suggested that viral load and inflammation are better controlled than in the untreated fatal case and that the virus is cleared without excessive inflammation. A scan of the dose-space of IL-10 and IFN- $\gamma$ suggested that a successful rescue can only be achieved if the doses of IL-10 and IFN- $\gamma$ are confined to a small region (Fig. S4).

The above results were based on the best fit from $\mathrm{H} 3$ and are consistent to those obtained from H5 (Fig. S5). We conclude that a therapy targeting the support and acceleration of $\mathrm{T}$ cell functionality should be accompanied with an intricately balanced anti-inflammatory treatment, as a medium level of TNF- $\alpha$ is necessary for antibody induction.

\section{Discussion}

Knowledge of human EBOV infections is limited. Although multiple lines of evidence pointed to the importance of a properly balanced early innate immune response $e^{3,12,20,26}$, the requirements for such a proper response in infected humans were not clear. Specifically, it was not clear whether a proper response depends on certain properties of the virus or the host. By calibrating a cytokine network to data from three groups of patients, i.e. fatal cases, survivors, and asymptomatic infections, we have shown here that the differences among the three groups cannot be explained by differential initial viral doses, viral replication rates and viral removal rates.

They can be explained, however, by differential immune responses. Specifically, a differential 
innate immune response alone $(\mathrm{H} 3)$ explained the data better than differential innate and adaptive immune responses (H5) did. In both $\mathrm{H} 3$ and $\mathrm{H} 5$, the rate of TNF- $\alpha$ induction by EBOV $\left(Q_{\mathrm{vf}}\right)$ in the three groups showed a sequence consistent with disease severity, which was not observed for other parameters. These results suggest that the fate decision of an EBOV infected patient relies on the ability to induce an early innate immune response, which subsequently triggers adaptive responses before it is too late. It is remarkable that despite the fate decisive role of the innate response, virus clearance completely relies on IFN- $\gamma$ and antibody dependent immune responses.

The reported inoculation period of EBOV infection is in the range of 2-20 days. The inoculation period associated with the data used in the mathematical model was estimated to be about 7 days $^{3,20,23}$. The results still hold true, if we start from an inoculation period of 14 days. However, with 3 days the model failed to fit the data. This delineates the range of validity of the proposed stratification and therapy strategy.

The presented model included a positive auto-feedback of IFN- $\gamma$ representing the stimulating influence of IFN- $\gamma$ on the differentiation of naive CD4+ T cells into Th1 cells and on the development of CD8+ T cells, both of which are the main producers of IFN- $\gamma$. While there is evidence that TNF- $\alpha$ induces an autocrine loop stabilizing the expression of pro-inflammatory signals including TNF- $\alpha$ itself ${ }^{27}$, we found that the auto-feedback of TNF- $\alpha$ in the model, which represents the whole innate immune response, is not necessary for numerical optimization. While the reason for this asymmetric model structure remains to be clarified, there is in vitro evidence that EBOV-induced pro-inflammatory cytokine secretion from human monocytes ${ }^{6}$ is not altered when a TNF- $\alpha$ antagonist is added to the culture, which is in line with the model 
structure.

We took IFN- $\gamma$ mainly as a surrogate of the function of cytotoxic T lymphocytes and Th1 cells. This is, in general, not an accurate approximation, as also NK cells secrete IFN- $\gamma$ upon activation. However, in the special case of Zaire EBOV infection, NK cells have been shown to be depleted much faster than cytotoxic T lymphocyte in nonhuman primates ${ }^{12,28}$ and, hence, can be neglected for later control of the virus in comparison to cytotoxic T cells.

The numerical optimization studies suggested that IFN- $\gamma$ and antibody have a similar virus clearance capacity. This quantification of the capacity of cellular and humoral immunity is consistent with experimental results showing that both CD8+ T cells and antibody can convey protection from Ebola virus ${ }^{13,29}$, that Ebola vaccine provided high protection against disease ${ }^{30}$, and that exogenous IFN- $\gamma$ protected mice from lethal mouse-adapted EBOV challenge ${ }^{31}$. However, the model suggested that IFN- $\gamma$ increases two days later in fatal cases than antibody does in survivors (Fig. 5). A delayed induction of IFN- $\gamma$ was associated with a weak induction of IFN- $-\gamma$ by virus $\left(Q_{\mathrm{fg}}\right)$ or TNF- $\alpha\left(Q_{\mathrm{vg}}\right)$ in comparison to IFN- $\nu$ auto-induction $\left(Q_{\mathrm{gg}}\right)$. This might be related to the known impaired function of human dendritic cells in vivo, which fail to secrete cytokines in response to EBOV infection, leading to impaired function and anomalous maturation ${ }^{10,12}$.

The model predicted the dynamics of TNF- $\alpha$ induction to be a main difference among fatal cases, survivors and asymptomatic infections, which suggests a central role of the innate immune response in the early stages and the subsequent earlier transition to humoral responses in vivo. This knowledge can be used to stratify EBOV patients at the time of presentation in the clinics, i.e. at the time of onset of symptoms, into potential survivors and fatal cases depending on the measured blood concentration of TNF- $\alpha$. 
The cases classified as fatal may be rescued by an EBOV therapy. In the model it is possible to rescue the in silico patients by a combined IFN- $y$ and IL-10 therapy. However, this treatment strategy has to be translated into the in vivo case: Due to the necessary reductionist approach in silico, IFN- $\gamma$ and IL-10 therapy stand for therapies targeting in vivo immune strategies. Therefore, a one-to-one translation of the findings into clinical therapy is limited. However, the use of mono-cytokine therapies in clinical practice is well established, e.g. TNF blockade for the therapy of autoimmunity ${ }^{32}$, or, type I interferon therapy for the treatment of viral infections like hepatitis $^{33}$ and, at least experimentally, IL-10 therapy as anti-inflammatory approach ${ }^{34}$. Direct IFN- $\gamma$ therapy is also established for prevention of infection in patients with chronic granulomatosis, an innate immunity defect ${ }^{35}$. Interferon therapy has also been discussed and partly tested for the treatment of Ebola ${ }^{36}$, but also other viral infections, like Dengue, parasitosis $^{37,38}$, and Tuberkulosis ${ }^{39}$. From a mechanistic point of view, interferon- $\gamma$ therapy might be replaced by type I interferon therapy in the present context, provided it is given early enough. The paradigm that targeting one single mediator will modulate the whole system in a beneficial way was also followed. For example, application of type I interferon strengthens the anti-viral effector function of the immune system ${ }^{36,40,41}$ and is reflected in higher levels of the effector cytokine IFN- $\gamma$. This means that the clinical practice also reflects a reductionist approach, substituting main modulators for different parts of effector mechanisms. As our model shows, strengthening the anti-inflammatory pathway, e.g. by IL-10 treatment and/or increasing anti-viral mechanisms, e.g. by substituting type I interferons with the right timing could help to increase survival of Ebola infected individuals.

In conclusion, the model suggests that it possible to stratify patients at high risk of fatal infections 
early on at the time of onset of first symptoms when patients would normally present themselves at the clinics. Further, the model predicts that it is possible to rescue patients classified as fatal EBOV infections by promoting cytotoxic $\mathrm{T}$ cell responses, and avoiding undesirable strong inflammatory responses by strengthening anti-inflammatory pathways. The model therefore confirms preclinical and clinical experience and might help to optimize host-directed therapy for Ebola infection.

\section{Acknowledgement}

This work was supported by the Helmholtz Initiative on Personalized Medicine - iMed.

\section{References}

1 Centers for Disease Control. Outbreak of Ebola Viral Hemorrhagic Fever -- Zaire, 1995. Morb Mortal Wkly Rep 1995; 44: 381-2.

2 Georges A-J, Leroy EM, Renaut AA, et al. Ebola Hemorrhagic Fever Outbreaks in Gabon, 19941997: Epidemiologic and Health Control Issues. J Infect Dis 1999; 179: S65-75.

3 Leroy EM, Baize S, Debre P, Lansoud-Soukate J, Mavoungou E. Early immune responses accompanying human asymptomatic Ebola infections. Clin Exp Immunol 2001; 124: 453-60.

4 Villinger F, Rollin PE, Brar SS, et al. Markedly Elevated Levels of Interferon (IFN)- $\nu$, IFN- $\alpha$, Interleukin (IL)-2, IL-10, and Tumor Necrosis Factor- $\alpha$ Associated with Fatal Ebola Virus Infection. J Infect Dis 1999; 179: S188-91.

5 Wauquier N, Becquart P, Padilla C, Baize S, Leroy EM. Human Fatal Zaire Ebola Virus Infection Is Associated with an Aberrant Innate Immunity and with Massive Lymphocyte Apoptosis. PLOS Negl Trop Dis 2010; 4: e837.

6 Ströher U, West E, Bugany H, Klenk H-D, Schnittler H-J, Feldmann H. Infection and Activation of Monocytes by Marburg and Ebola Viruses. J Virol 2001; 75: 11025-33.

7 Basler CF, Wang X, Mühlberger E, et al. The Ebola virus VP35 protein functions as a type I IFN antagonist. Proc Natl Acad Sci 2000; 97: 12289-12294. 
8 Gupta M, Mahanty S, Ahmed R, Rollin PE. Monocyte-Derived Human Macrophages and Peripheral Blood Mononuclear Cells Infected with Ebola Virus Secrete MIP-1 $\alpha$ and TNF- $\alpha$ and Inhibit Poly-IC-Induced IFN- $\alpha$ in Vitro. Virology 2001; 284: 20-5.

9 Harcourt BH, Sanchez A, Offermann MK. Ebola Virus Inhibits Induction of Genes by Double-Stranded RNA in Endothelial Cells. Virology 1998; 252: 179-88.

10 Bosio CM, Aman MJ, Grogan C, et al. Ebola and Marburg Viruses Replicate in Monocyte-Derived Dendritic Cells without Inducing the Production of Cytokines and Full Maturation. J Infect Dis 2003; 188: 1630-8.

11 Mahanty S, Hutchinson K, Agarwal S, Mcrae M, Rollin PE, Pulendran B. Cutting Edge: Impairment of Dendritic Cells and Adaptive Immunity by Ebola and Lassa Viruses. J Immunol 2003; 170: 2797-801.

12 Geisbert TW, Hensley LE, Larsen T, et al. Pathogenesis of Ebola Hemorrhagic Fever in Cynomolgus Macaques: Evidence that Dendritic Cells Are Early and Sustained Targets of Infection. Am J Pathol 2003; 163: 2347-70.

13 Bradfute SB, Warfield KL, Bavari S. Functional CD8+ T Cell Responses in Lethal Ebola Virus Infection. J Immunol 2008; 180: 4058-66.

14 Gibb TR, Bray M, Geisbert TW, et al. Pathogenesis of Experimental Ebola Zaire Virus Infection in BALB/c Mice. J Comp Pathol 2001; 125: 233-42.

15 Sanchez A, Lukwiya M, Bausch D, et al. Analysis of Human Peripheral Blood Samples from Fatal and Nonfatal Cases of Ebola (Sudan) Hemorrhagic Fever: Cellular Responses, Virus Load, and Nitric Oxide Levels. J Virol 2004; 78: 10370-7.

16 Ksiazek TG, Rollin PE, Williams AJ, et al. Clinical Virology of Ebola Hemorrhagic Fever (EHF): Virus, Virus Antigen, and IgG and IgM Antibody Findings among EHF Patients in Kikwit, Democratic Republic of the Congo, 1995. J Infect Dis 1999; 179: S177-87.

17 Onyango CO, Opoka ML, Ksiazek TG, et al. Laboratory Diagnosis of Ebola Hemorrhagic Fever during an Outbreak in Yambio, Sudan, 2004. J Infect Dis 2007; 196: S193-8.

18 Baize S, Leroy EM, Georges-Courbot M-C, et al. Defective humoral responses and extensive intravascular apoptosis are associated with fatal outcome in Ebola virus-infected patients. Nat Med 1999; 5: 423-6.

19 Ruibal P, Oestereich L, Lüdtke A, et al. Unique human immune signature of Ebola virus disease in Guinea. Nature 2016; 533: 100-4.

20 Baize S, Leroy EM, Georges AJ, et al. Inflammatory responses in Ebola virus-infected patients. Clin Exp Immunol 2002; 128: 163-8.

21 Bray M, Mahanty S. Ebola Hemorrhagic Fever and Septic Shock. J Infect Dis 2003; 188: 1613-7. 
22 Hensley LE, Young HA, Jahrling PB, Geisbert TW. Proinflammatory response during Ebola virus infection of primate models: possible involvement of the tumor necrosis factor receptor superfamily. Immunol Lett 2002; 80: 169-79.

23 Leroy $\mathrm{E}$, Baize $\mathrm{S}$, Volchkov $\mathrm{V}$, et al. Human asymptomatic Ebola infection and strong inflammatory response. The Lancet 2000; 355: 2210-5.

24 Banton S, Roth Z, Pavlovic M. Mathematical Modeling of Ebola Virus Dynamics as a Step towards Rational Vaccine Design. In: Herold KE, Vossoughi J, Bentley WE, eds. 26th Southern Biomedical Engineering Conference SBEC 2010, April 30 - May 2, 2010, College Park, Maryland, USA. Springer Berlin Heidelberg, 2010: 196-200.

25 Nguyen VK, Binder SC, Boianelli A, Meyer-Hermann M, Hernandez-Vargas EA. Ebola virus infection modeling and identifiability problems. Infect Dis 2015; 6: 257.

26 Mahanty S, Gupta M, Paragas J, Bray M, Ahmed R, Rollin PE. Protection from lethal infection is determined by innate immune responses in a mouse model of Ebola virus infection. Virology 2003; 312: 415-24.

27 Yarilina A, Park-Min K-H, Antoniv T, Hu X, Ivashkiv LB. TNF activates an IRF1-dependent autocrine loop leading to sustained expression of chemokines and STAT1-dependent type I interferon-response genes. Nat Immunol 2008; 9: 378-87.

28 Reed DS, Hensley LE, Geisbert JB, Jahrling PB, Geisbertl TW. Depletion of Peripheral Blood T Lymphocytes and NK Cells During the Course of Ebola Hemorrhagic Fever in Cynomolgus Macaques. Viral Immunol 2004; 17: 390-400.

29 McElroy AK, Akondy RS, Davis CW, et al. Human Ebola virus infection results in substantial immune activation. Proc Natl Acad Sci 2015; 112: 4719-24.

30 Henao-Restrepo AM, Camacho A, Longini IM, et al. Efficacy and effectiveness of an rVSV-vectored vaccine in preventing Ebola virus disease: final results from the Guinea ring vaccination, open-label, cluster-randomised trial (Ebola Ça Suffit!). The Lancet 2016; 0. DOI:10.1016/S0140-6736(16)32621-6.

31 Rhein BA, Powers LS, Rogers K, et al. Interferon- $\gamma$ Inhibits Ebola Virus Infection. PLOS Pathog 2015; 11: e1005263.

$32 \mathrm{Nam}$ JL, Ramiro S, Gaujoux-Viala C, et al. Efficacy of biological disease-modifying antirheumatic drugs: a systematic literature review informing the 2013 update of the EULAR recommendations for the management of rheumatoid arthritis. Ann Rheum Dis 2014; 73: 516-28.

33 Webster DP, Klenerman P, Dusheiko GM. Hepatitis C. The Lancet 2015; 385: 1124-35.

34 Fioranelli M, Grazia RM. Twenty-five years of studies and trials for the therapeutic application of IL-10 immunomodulating properties. From high doses administration to low dose medicine 
new paradigm. 2014. http://www.oatext.com/pdf/JIC-1-102.pdf (accessed Jan 18, 2017).

35 Roos D. Chronic granulomatous disease. Br Med Bull 2016; 118: 50-63.

36 WHO Ebola drug test database. http://www.who.int/medicines/ebola-treatment/test-database/en/ (accessed Jan 20, 2017).

37 Bucheton B, MacLeod A, Jamonneau V. Human host determinants influencing the outcome of Trypanosoma brucei gambiense infections. Parasite Immunol 2011; 33: 438-47.

38 Wang Y, Chen X, Cao W, Shi Y. Plasticity of mesenchymal stem cells in immunomodulation: pathological and therapeutic implications. Nat Immunol 2014; 15: 1009-16.

39 Kaufmann SHE, Lange $C$, Rao $M$, et al. Progress in tuberculosis vaccine development and host-directed therapies--a state of the art review. Lancet Respir Med 2014; 2: 301-20.

40 Krishnan MN, Garcia-Blanco MA. Targeting Host Factors to Treat West Nile and Dengue Viral Infections. Viruses 2014; 6: 683-708.

41 Foster GR. Pegylated Interferons for the Treatment of Chronic Hepatitis C. Drugs 2010; 70: 147-65. 
Fig. 1

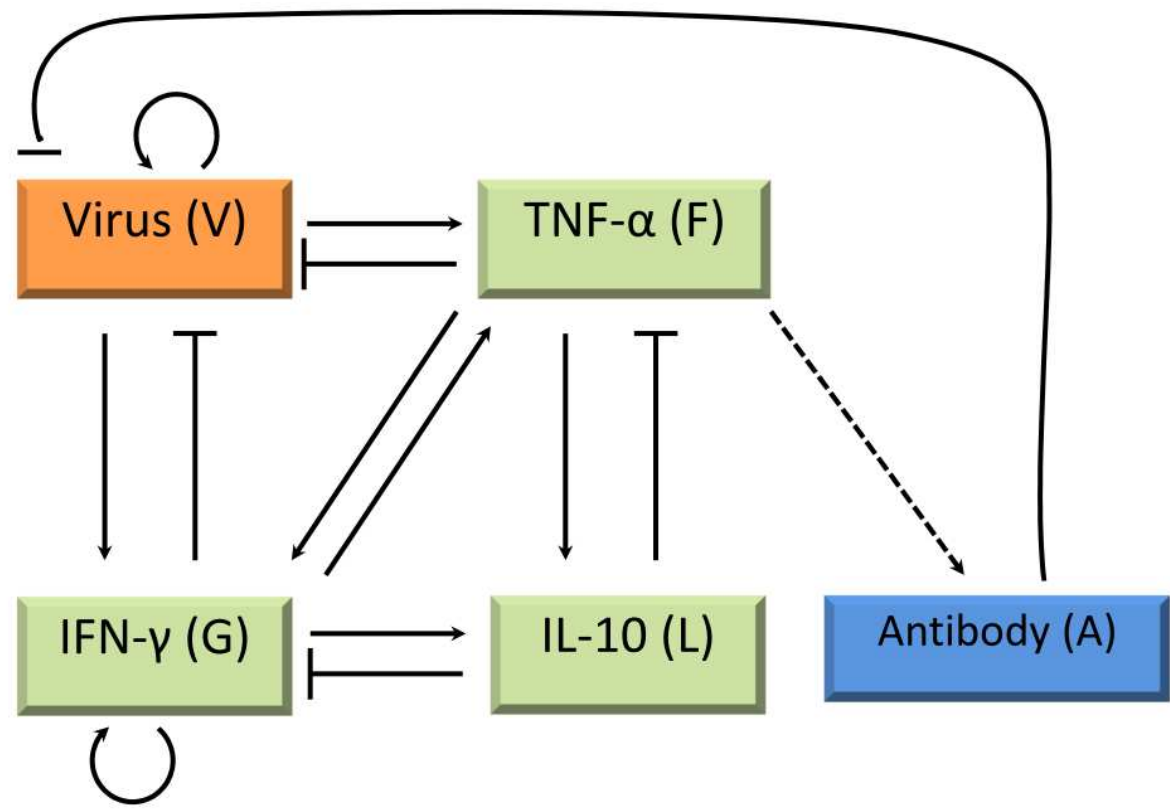

Fig. 1. Scheme of the cytokine network model. Arrows represent induction, lines with bar represent inhibition. The broken arrow (from TNF- $\alpha$ to antibody) stands for a delay of antibody induction. 
Fig. 2
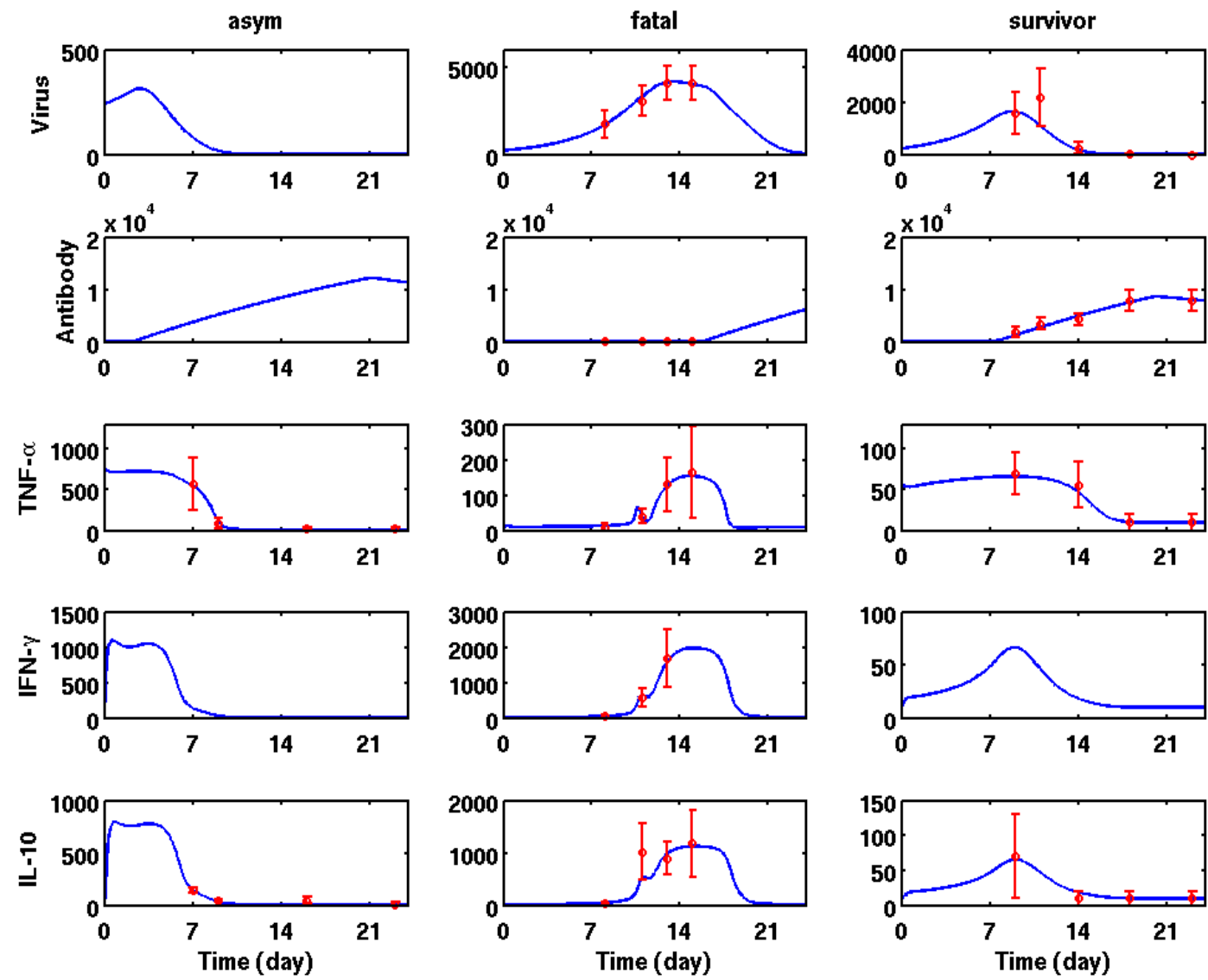

Fig. 2 Differential innate immune response (H3) explains best the data of the three groups simultaneously. Each column is corresponding to one group. Note that the fatalities succumbed on day 16 or 17. Circles with error-bar are measurements, curves are the simulation result. 
Fig. 3
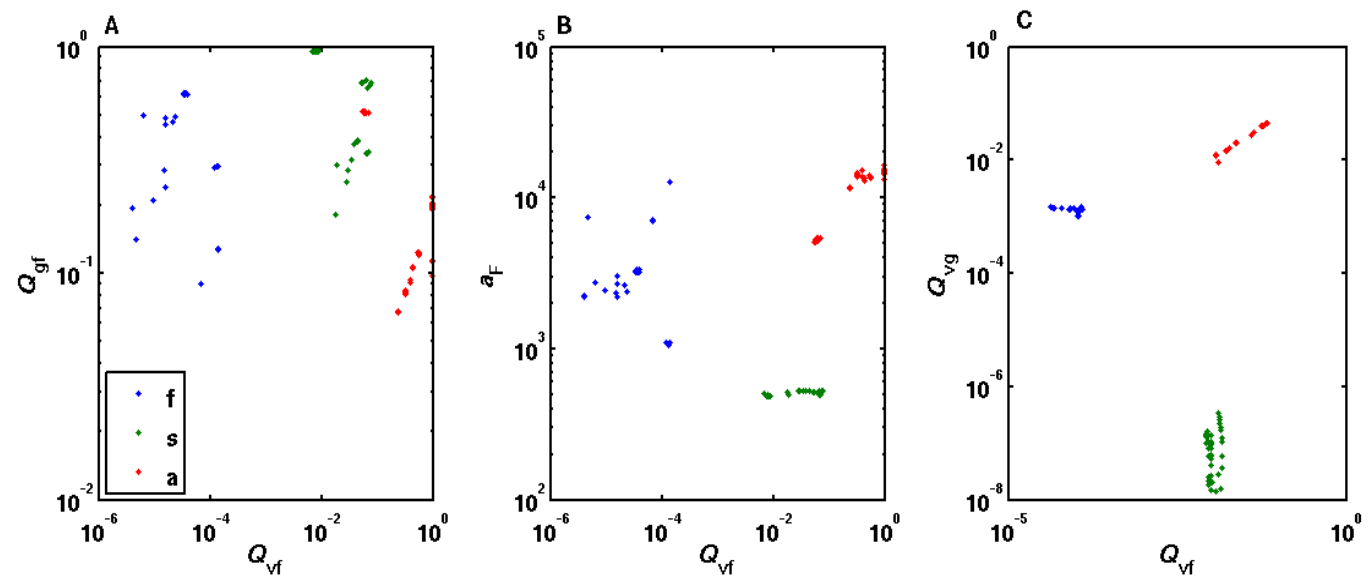

Fig. 3. Differential parameters of the three groups (f, fatalities; s, survivors; a, asymptomatic

infections) from all the accepted fitting results ( $\mathrm{A}$ and $\mathrm{B}$ for $\mathrm{H} 3, \mathrm{C}$ for $\mathrm{H} 5$ ). Only $Q_{\mathrm{vf}}$, which represents TNF- $\alpha$ induction by EBOV, showed a sequence consistent with disease severity in both $\mathrm{H} 3$ and $\mathrm{H} 5$. Please note that $a_{\mathrm{F}}$ is not a free parameter during the optimization procedures for $\mathrm{H} 3$. It is influenced indirectly by $Q_{\mathrm{gf}}$ in the steady state constraint of TNF- $\alpha$.. 
Fig. 4

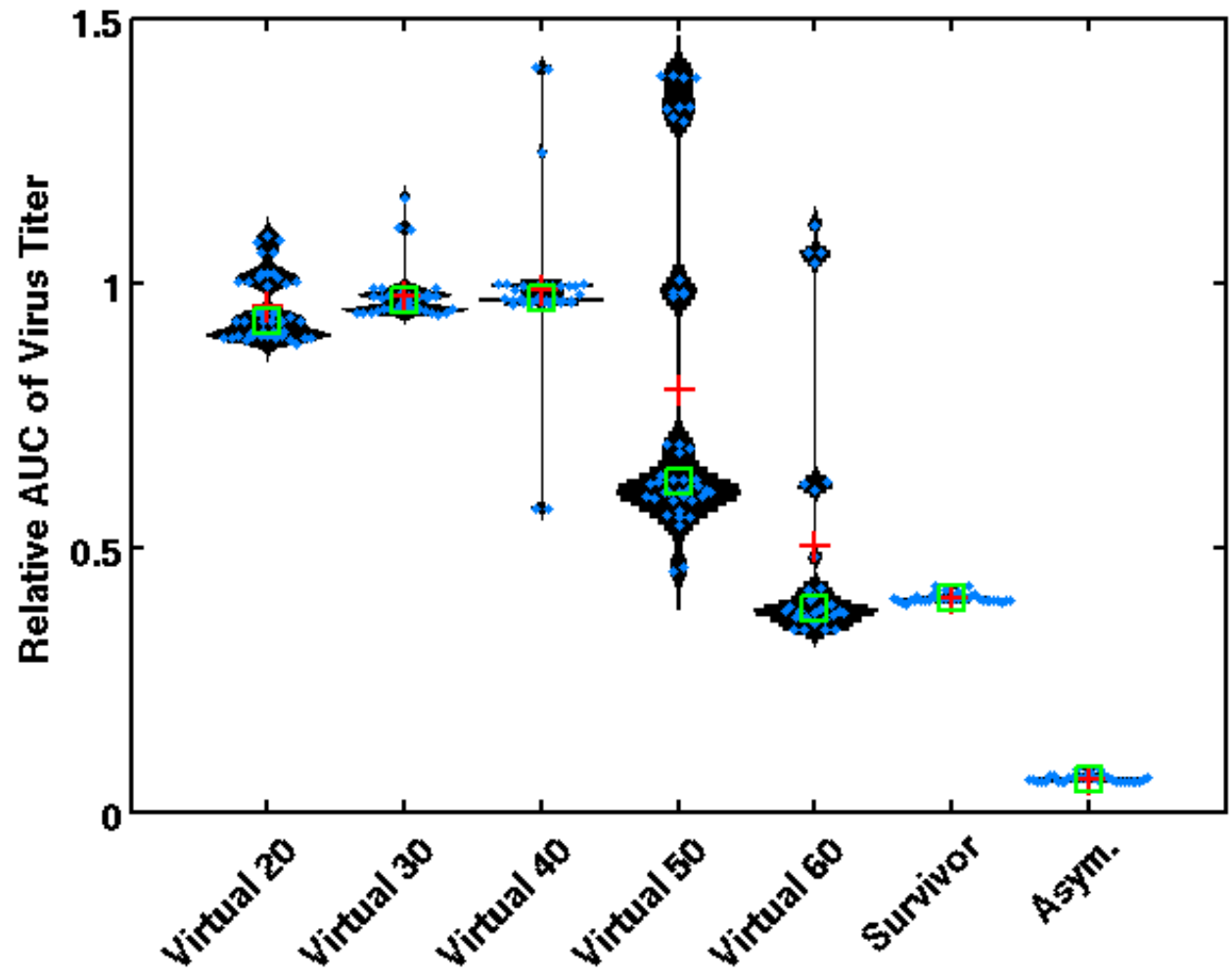

Fig. 4. Stratification of virtual patients based on early TNF- $\alpha$ levels. The viral load of virtual patients, survivors and asymptomatic infections, normalized by that of fatal cases are shown. Blue points are results from 100 independent numerical optimizations. Green squares and the red crosses denote the mean and the median value, respectively. "Virtual X" means the virtual patient whose TNF level is X pg/ml on day 8 after infection. AUC is calculated from day 0 to 15 (one day before fatal cases succumbed to the disease.) 
Fig. 5

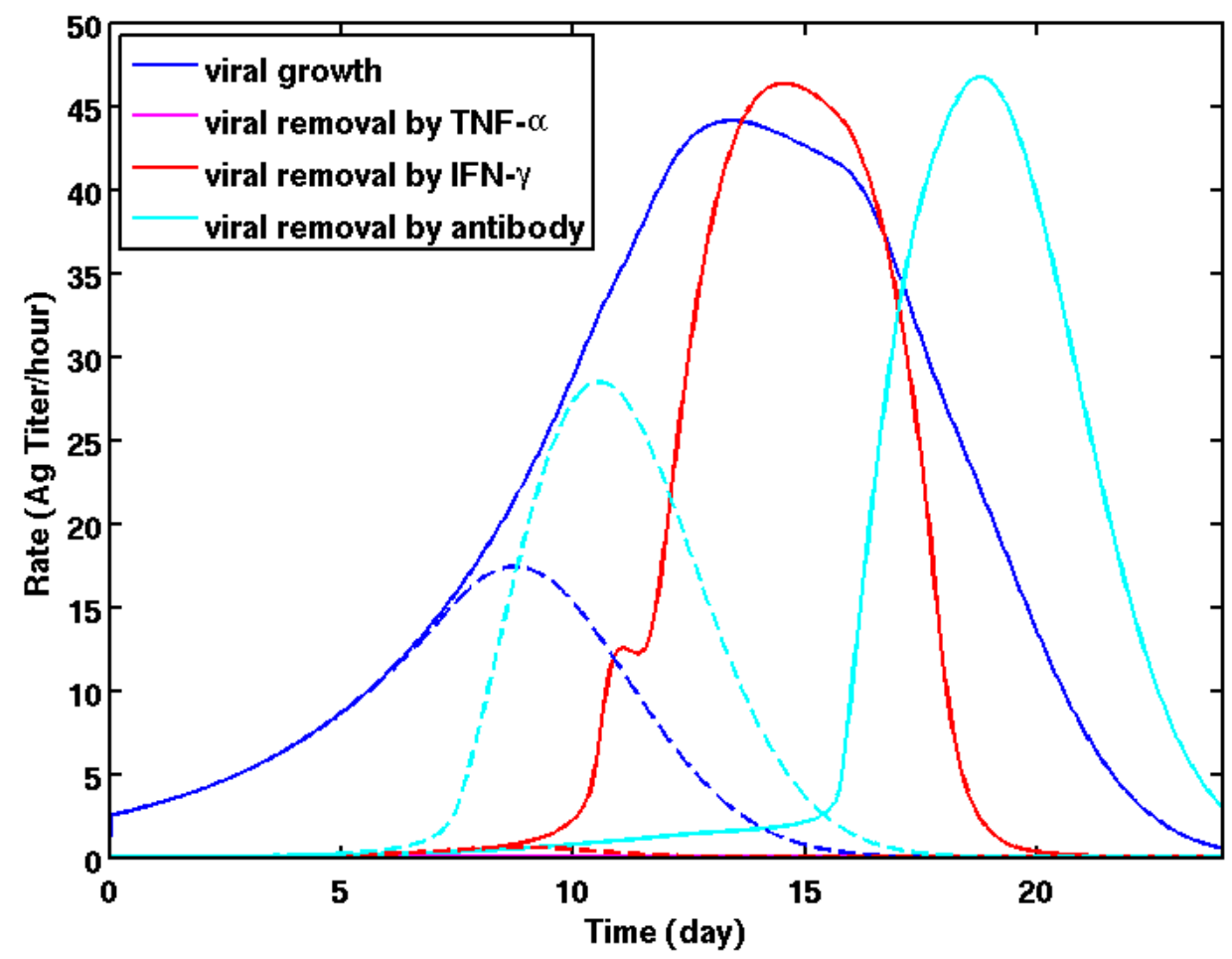

Fig. 5. Natural history of EBOV growth rate (blue), and rates of removal by immune factors (see figure inset) in the fatalities (full line) and survivors (broken line). TNF- $\alpha$ induced viral clearance is negligible in both groups of patient. Although insufficient, IFN- $\gamma$ was the main defense arm against EBOV in the fatalities, while antibody removed most of the viruses in the survivors. The fatalities succumbed on day 16 or 17. These curves were based on the best fit in Fig. 2 . 
Fig. 6
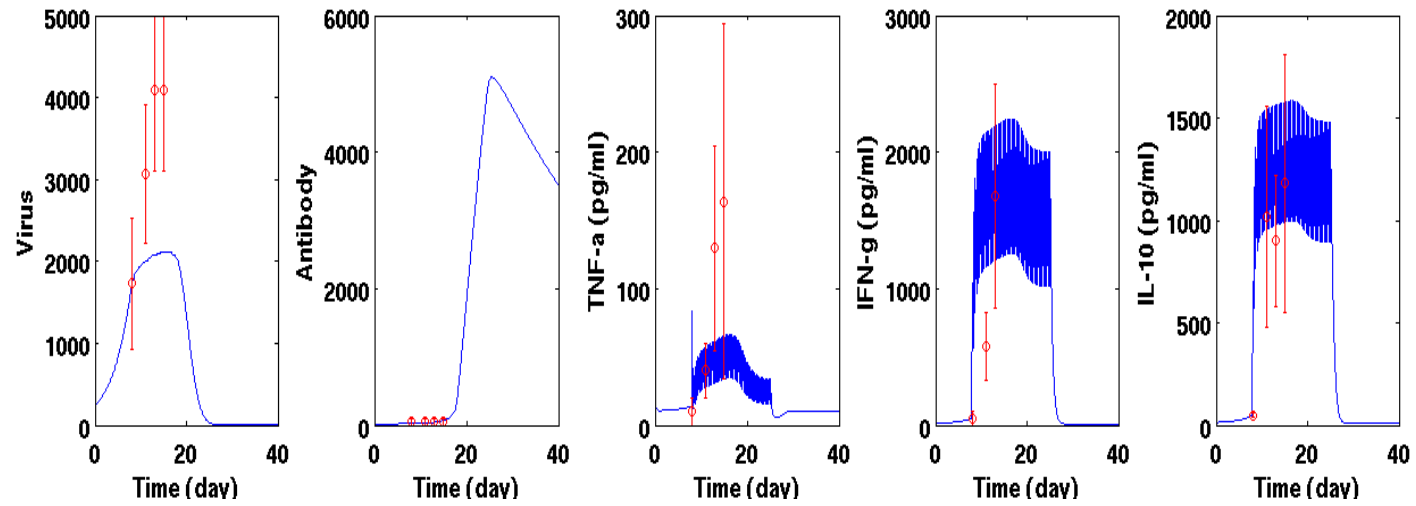

Fig. 6 An example of the effects of the immune-interfering therapy. Exogenous IFN- $\gamma$ (a pulse of $1000 \mathrm{pg} / \mathrm{ml}$ every 8 hours) and IL-10 (a pulse of $600 \mathrm{pg} / \mathrm{ml}$ every 8 hours) were given to the in silico fatal patient to inhibit viral replication and suppress undesirable strong TNF- $\alpha$ upregulation. The in silico therapy started from day 8 and ended on day 25. Red circles with error bar are data of the fatalities without the immune-interfering therapy. Model parameter values were taken from the best fit in Fig. 2 . 


\section{Supplementary materials}

2 The supplementary material includes the details of the modeling method, the additional

3 hypotheses that have been tested, the Table of parameter values and the captions of the

4 supplementary figures.

\section{Method}

6 Under consideration of the available data, we took a reductionist approach in modeling immune

7 responses to EBOV infection. Instead of considering different cell types and their corresponding mechanisms in the immune defense, we took their prototype cytokines as surrogates of various aspects of the function of the immune system. Thus, TNF- $\alpha$ was taken as the surrogate of the innate immune response, IFN- $\gamma$ as that of Th1 and cytotoxic T lymphocytes, IgG as that of the humoral response and IL-10 as the surrogate of immune-regulatory responses. Patient data obtained during two Ebola outbreaks in Gabon in 1996 from the same virus strain ${ }^{1,2}$ were used to evaluate different hypotheses for predictive markers of disease progression.

Cytokine levels have been measured since clinical admission, until death or convalescence of the patients. Seven out of seventeen patients (survivors and fatal cases) were infected at the same time so that the time lapse between infection and clinical admission was clearly defined for these patients. For the rest of the patients, the same time lapse was assumed. Given the uncertainty in the inoculation time for these patients, we tested different inoculation times in the model. Antigen and antibody levels were reported as titer (dilution). The IFN- $\gamma$ level in fatalities dropped drastically 1 day before death, which was attributed to massive intravascular apoptosis ${ }^{1}$. Since the current model is not intended for this extreme situation, and since we were interested 
in our studies. The reported IFN- $\nu$ protein level in survivors was inconsistent with the trend of mRNA in peripheral blood mononuclear cells from the same patients. The former showed no activation while the latter showed upregulation during the period of viral clearance and clinic recovery ${ }^{1}$. To clarify the possible influence of the inconsistency in IFN- $p$ protein and mRNA data in survivors, we always carried out two parallel studies, either with or without IFN protein data in survivors. The results were consistent with each other. Certain reported cytokine levels were in the form "< $20 \mathrm{pg} / \mathrm{ml}$ ". In this instance, we took $10 \pm 10 \mathrm{pg} / \mathrm{ml}$ instead in the numerical studies.

In addition to the fatalities and survivors, asymptomatic human infections during the two outbreaks have been identified. We also included the data of asymptomatic infection in our studies. However, it appeared that the IgG antibody was measured with a different protocol ${ }^{3}$. In order to avoid any bias from the protocol of data acquisition, we didn't include the IgG data associated with the asymptomatic infection. For the asymptomatic cases, the infection time was inferred from reported first exposure to infection.

The interactions between all considered cytokines (Fig. 1) are modeled in a phenomenological way, i.e. by sigmoidal functions of the concentrations of the cytokines while neglecting the mediators and the mechanisms underlying each interaction.

\section{Virus}

Viral replication is modeled by logistic growth, with replication rate $p$ and carrying capacity $K$. The virus clearance capacities by TNF- $\alpha(F), \operatorname{IFN}-\gamma(G)$ and antibody $(A)$ are denoted by rate constants $R_{\mathrm{f}}, R_{\mathrm{g}}$ and $R_{\mathrm{a}}$, respectively. The equation for virus $V$ reads

$\frac{d V}{d t}=p V\left(1-\frac{V}{K}\right)-\left(R_{\mathrm{f}} F+R_{\mathrm{g}} G+R_{\mathrm{a}} A\right) V$. 


\section{Cytokines}

45 The dynamics of each cytokine are modeled by a production term and a degradation term. The

46 production term of each cytokine is a Goldbeter-Koshland function $(g)$ of the following form:

$g\left(r, j_{1}, j_{2}\right)=\frac{2 r j_{2}}{B+\sqrt{B^{2}-4(1-r) r j_{2}}}$,

$47 \quad B=1-r+j_{1}+j_{2} r$ $r=\frac{v_{1}}{v_{2}}$.

The Goldbeter-Koshland function is a monotonously increasing function of $r$, and has a sigmoidal shape. $r$ is the ratio between the effects of activator(s) and inhibitor(s), which are denoted by $v_{1}$ and $v_{2}$ respectively. In the case of multiple activators (inhibitors), the corresponding term of $v_{1}\left(v_{2}\right)$

51 is composed of linear combinations of each activator (inhibitor), together with the cross-terms up to the second order. The shape of the Goldbeter-Koshland function is determined by $j_{1}$ and $j_{2}$,

53 which represent the degree of nonlinearity of the activation and inhibition processes, 54 respectively. Note that larger values of $j_{1}\left(j_{2}\right)$ correspond to lower levels of nonlinearity in the activation (inhibition) process and make the Goldbeter-Koshland function smoother. The equations for the cytokines read:

$$
\frac{d F}{d t}=a_{\mathrm{f}} g\left(r_{\mathrm{f}}, j_{1 \mathrm{f}}, j_{2 \mathrm{f}}\right)-d_{\mathrm{f}} F,
$$

$57 \frac{d G}{d t}=a_{\mathrm{g}} g\left(r_{\mathrm{g}}, j_{1 \mathrm{~g}}, j_{2 \mathrm{~g}}\right)-d_{\mathrm{g}} G$, $\frac{d L}{d t}=a_{1} g\left(r_{1}, j_{11}, j_{21}\right)-d_{1} L$ 
$r_{\mathrm{f}}=\frac{v_{1 \mathrm{f}}}{v_{2 \mathrm{f}}}=\frac{Q_{\mathrm{vf}} V+Q_{\mathrm{gf}} G+Q_{v g f} V G}{Q_{\mathrm{lf}} L}$,

$59 \quad r_{\mathrm{g}}=\frac{v_{1 \mathrm{~g}}}{v_{2 \mathrm{~g}}}=\frac{Q_{\mathrm{vg}} V+Q_{\mathrm{fg}} F+Q_{\mathrm{gg}} G+Q_{\mathrm{fgg}} F G+Q_{\mathrm{fvg}} F V+Q_{\mathrm{gvg}} G V}{Q_{\mathrm{lg}} L}$,

$r_{1}=\frac{v_{11}}{v_{21}}=\frac{Q_{\mathrm{fl}} F+Q_{\mathrm{gl}} G+Q_{\mathrm{fgl}} F G}{1}$

$Q_{x y}$ denotes the contribution of $x$ to the induction (inhibition) of y. $Q_{x y z}$ denotes the synergistic

61 contribution of $x$ and $y$ to the induction (inhibition) of $z$ and is defined as $Q_{x y z}=Q_{x z} Q_{y z}$. $d_{f}, d_{g}$ and $d_{l}$

are the degradation rates of TNF- $\alpha$, IFN- $-\gamma$ and IL-10, respectively. $a_{\mathrm{f}}, a_{\mathrm{g}}$ and $a_{\mathrm{I}}$ are determined by

steady state. The steady state levels of the cytokines were estimated based on the reported

values for controls. TNF- $\alpha$ and IL-10 in the controls were reported as " $<20 \mathrm{pg} / \mathrm{ml}^{\prime 2}{ }^{24}$. IFN- $-\gamma$ in the

controls were below the limits of instrument sensitivity ${ }^{21}$. Consequently, we took $10 \mathrm{pg} / \mathrm{ml}$ as the

steady state level for each cytokine.

\section{Antibody}

The induction of antibody $A$ is induced by TNF- $\alpha$ with a delay. The delay is modeled via the linear

train trick $\left(F_{1} \sim F_{4}\right)$. The equations read:

$$
\frac{d A}{d t}=a_{\mathrm{a}} g\left(F_{4}, j_{\mathrm{a}}, j_{\mathrm{a}}\right)-d_{\mathrm{a}} A,
$$

$70 \quad \frac{d F_{1}}{d t}=k\left(F-F_{1}\right)$,

$$
\frac{d F_{\mathrm{i}+1}}{d t}=k\left(F_{\mathrm{i}}-F_{\mathrm{i}+1}\right), i=1,2,3 \text {. }
$$


mean square (RMS) difference between model simulation ( $\hat{y})$ and the data (y),

$$
\mathrm{RMS}=\sqrt{\sum_{i=1}^{n_{\mathrm{f}}} \frac{\left(\hat{y}_{\mathrm{f}, \mathrm{i}}-y_{\mathrm{f}, \mathrm{i}}\right)^{2}}{\sigma_{\mathrm{f}, \mathrm{i}}^{2}}+\sum_{i=1}^{n_{\mathrm{s}}} \frac{\left(\hat{y}_{\mathrm{s}, \mathrm{i}}-y_{\mathrm{s}, \mathrm{i}}\right)^{2}}{\sigma_{\mathrm{s}, \mathrm{i}}^{2}}+\sum_{i=1}^{n_{\mathrm{a}}} \frac{\left(\hat{y}_{\mathrm{a}, \mathrm{i}}-y_{\mathrm{a}, \mathrm{i}}\right)^{2}}{\sigma_{\mathrm{a}, \mathrm{i}}^{2}}} .
$$

where suffix $f, s$ and a denote fatality, survivor and asymptomatic infection, respectively, $\sigma$ denotes the standard deviation of the measured data point, and $n$ denotes the number of data points.

All the simulation work was done based on the SBPD toolbox for Matlab ${ }^{4}$. The SBPD toolbox was modified in parts for this purpose. A differential evolution based global optimizer was employed to fit the parameters in the model. The optimizer returns a population of parameter-vectors that give rise to acceptable fitting results. Moreover, each optimization task was repeated 100 times. As a phenomenological restriction, we excluded those fitting results where the production rate of any cytokine at resting state was less than one thousandth of the maximal rate. We also varied this restriction to two or five thousand and found no qualitative difference in the results. We took not only the best fitting result for further analyses, but also those fittings that are acceptable based on the Akaike information criterion (AIC) with a relative likelihood more than 0.368 (corresponding to 2 units difference in AIC). We further made sure that the fitting results kept for analysis were well separated in the parameter space in terms of the euclidean distance by filtering out very near solutions.

\section{Reference of the method section}

1 Baize S, Leroy EM, Georges-Courbot M-C, et al. Defective humoral responses and extensive intravascular apoptosis are associated with fatal outcome in Ebola virus-infected patients. Nat Med 1999; 5: 423-6. 
972 Baize S, Leroy EM, Georges AJ, et al. Inflammatory responses in Ebola virus-infected patients.

98 Clin Exp Immunol 2002; 128: 163-8.

993 Leroy E, Baize S, Volchkov V, et al. Human asymptomatic Ebola infection and strong 100 inflammatory response. The Lancet 2000; 355: 2210-5.

1014 Schmidt H. SBaddon: high performance simulation for the Systems Biology Toolbox for MATLAB.

102 Bioinformatics 2007; 23: 646-7. 
105 Additionally tested hypotheses (related to P5 paragraph $106 \mathbf{2}$ in the main text)

107 A combination of $\mathrm{H} 1$ and $\mathrm{H} 2$, with the four parameters (initial viral dose, $p, R_{\mathrm{f}}$ and $R_{\mathrm{g}}$ ) being

108 different in the three groups, again failed in explaining the data. A variation of $\mathrm{H} 4$, with $Q_{\mathrm{vg}}$ and $j_{1 \mathrm{~g}}$

109 being the differential parameters, failed as well. A variation of $\mathrm{H} 3$, where $Q_{\mathrm{vf}}$ and $j_{1 \mathrm{f}}$ are the

110 differential parameters, explained the data with the relative likelihood of 0.69 . 
Table 1 Parameter values for hypotheses H3 and H5

\begin{tabular}{|c|c|c|}
\hline \multirow[t]{2}{*}{ Symbols } & \multicolumn{2}{|c|}{ Value (description or unit) } \\
\hline & H3 & H5 \\
\hline \multicolumn{3}{|c|}{ TNF- $\alpha$ induction } \\
\hline \multirow[t]{3}{*}{$Q_{\mathrm{vf}}$} & $0.055,0.39,1$ (a) & $0.012,0.015,0.055$ (a) \\
\hline & $0.007,0.03,0.07(\mathrm{~s})$ & $8.57 \mathrm{e}-3,9.60 \mathrm{e}-3,0.013(\mathrm{~s})$ \\
\hline & $4 e-6,3.45 e-5,1.4 e-4$ (f) & $4.51 e-5,7.04 e-5,1.14 e-4(f)$ \\
\hline \multirow[t]{3}{*}{$Q_{\mathrm{gf}}$} & $0.08,0.20,0.52$ (a) & \multirow{3}{*}{$1,1,3.3$} \\
\hline & $0.25,0.67,0.96(\mathrm{~s})$ & \\
\hline & $0.12,0.49,0.63$ (f) & \\
\hline$j_{1 f}$ & $1.50,5.44,8.0$ & $22.48,24.47,27.70$ \\
\hline$j_{2 f}$ & $0.01,0.01,0.01$ & $0.01,0.01,0.01$ \\
\hline$d_{f}$ & \multicolumn{2}{|c|}{$6.932\left(\right.$ hour $\left.^{-1}\right)$} \\
\hline \multicolumn{3}{|c|}{ IFN- $\gamma$ induction } \\
\hline \multirow[t]{3}{*}{$Q_{\mathrm{vg}}$} & \multirow{3}{*}{$9.4 e-4,1 e-3,1.5 e-3$} & $9.2 \mathrm{e}-3,0.013,0.040(\mathrm{a})$ \\
\hline & & $0,0,0(s)$ \\
\hline & & $1 e-3,1 e-3,1 e-3(f)$ \\
\hline$Q_{\mathrm{fg}}$ & $0,3.82 e-5,5 e-3$ & $0,0,5.07 \mathrm{e}-6$ \\
\hline$Q_{\mathrm{gg}}$ & $0.09,0.82,2.10$ & $0.81,1.10,1.26$ \\
\hline$j_{1 \mathrm{~g}}$ & $3.53,32.15,83.74$ & $38.26,79.10,86.28$ \\
\hline
\end{tabular}




\begin{tabular}{|c|c|c|}
\hline$j_{2 g}$ & $0.01,0.01,0.01$ & $0.01,0.015,0.015$ \\
\hline$d_{g}$ & \multicolumn{2}{|c|}{0.0866 (hour $^{-1}$ ) } \\
\hline \multicolumn{3}{|c|}{ IL-10 induction } \\
\hline$Q_{\mathrm{fl}}$ & $0,0.03,0.1$ & $8.5 e-5,2.1 e-4,3.5 e-3$ \\
\hline$Q_{\mathrm{g} 1}$ & $5 e-3,0.061,0.17$ & $6.5 e-4,1.5 e-3,0.024$ \\
\hline$j_{11}$ & $17.8,90,90$ & $1.45,64.40,77.30$ \\
\hline$j_{21}$ & $0.18,0.79,1.97$ & $1.14,2.78,48.22$ \\
\hline$d_{1}$ & & $\left(\right.$ hour $\left.^{-1}\right)$ \\
\hline \multicolumn{3}{|c|}{ Antibody induction } \\
\hline$Q_{\mathrm{fa}}$ & $0.023,0.023,0.024$ & $0.026,0.027,0.028$ \\
\hline$j_{1 \mathrm{a}}$ & $0.01,0.01,0.01$ & $0.01,0.01,0.01$ \\
\hline$a_{\mathrm{a}}$ & $35.0,35.62,36.89$ & $32.7,34.8,35.3$ \\
\hline $\mathrm{k}$ & $0.025,0.025,0.03$ & $0.023,0.023,0.024$ \\
\hline$d_{\mathrm{a}}$ & \multicolumn{2}{|c|}{0.0012 (hour $^{-1}$ ) } \\
\hline \multicolumn{3}{|c|}{ Viral growth } \\
\hline$V_{1}$ & $27.87,141.96,237.42$ & $152.77,187.22,193.38$ \\
\hline K & $1 \mathrm{e} 7,1.7 \mathrm{e} 9,7.5 \mathrm{e} 9$ & $1 \mathrm{e} 7,5.7 \mathrm{e} 8,5.7 \mathrm{e} 9$ \\
\hline $\mathrm{p}$ & $0.01,0.012,0.02$ & $0.011,0.012,0.012$ \\
\hline$R_{\mathrm{f}}$ & $0,0,4.08 \mathrm{e}-6$ & $0,0,0$ \\
\hline$R_{\mathrm{g}}$ & $5.75 e-6,6.93 e-6,1.2 e-5$ & $5.10 e-6,5.59 e-6,6.38 e-6$ \\
\hline$R_{\mathrm{a}}$ & $9.0 e-6,9.6 e-6,1.1 e-5$ & $9.22 e-6,9.27 e-6,9.49 e-6$ \\
\hline
\end{tabular}

113 Values of fitted parameters are reported as a triplet of minimal, median and maximal values from 
114 all the accepted fitting results. Values less than 1 e- 6 are reported as 0 . The last data point of

115 IFN- $\gamma$ in survivors was not included for this parameter set. 


\section{Supplementary figure captions}

118 Fig. S1 All the accepted fitting results from $\mathrm{H3}$, coded by the color of the curves.

119 Fig. S2 The best fitting results from $\mathrm{H} 5$

120 Fig. S3 All the accepted fitting results from $\mathrm{H} 5$, coded by the color of the curves.

121 Fig. S4. Same as Fig. 7 in the main text, except that model parameters are based on the best fit

122 from $\mathrm{H} 5$.

123 
Fig. S1.
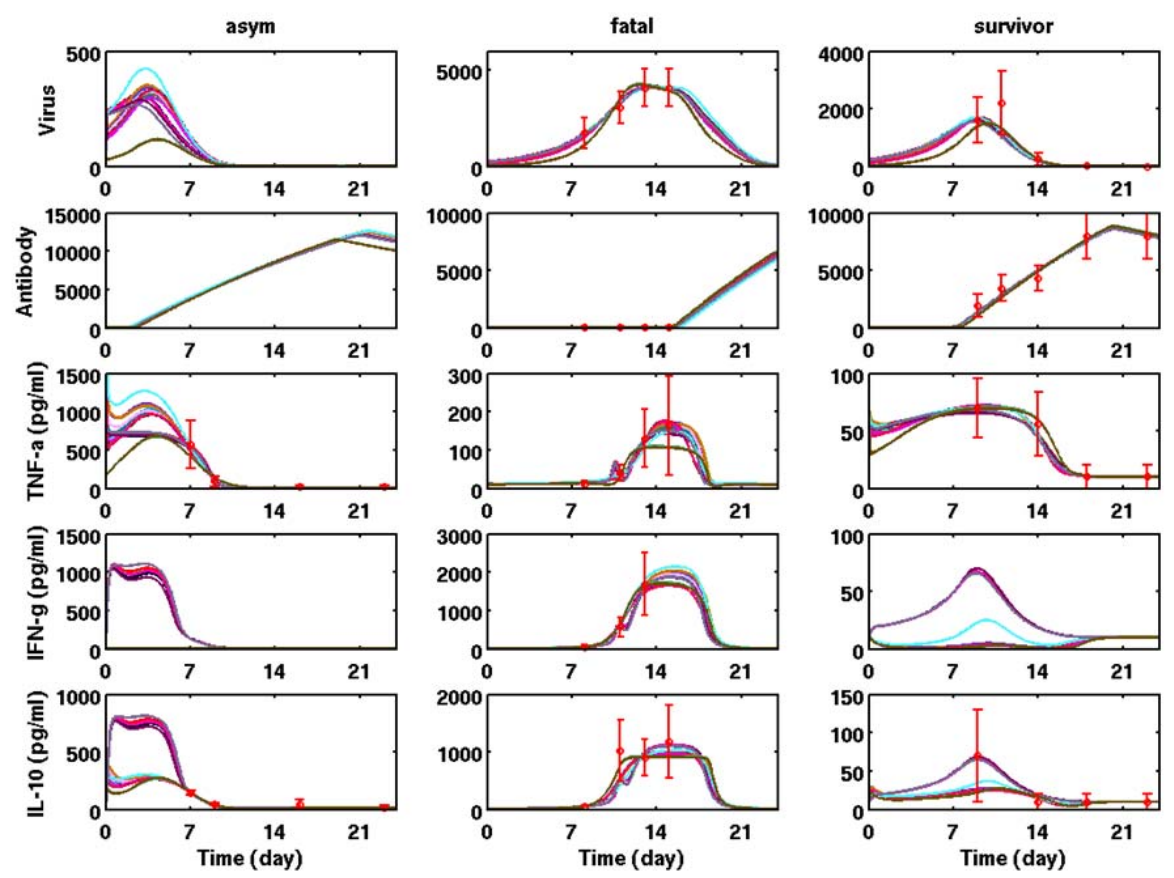

125

126

Fig. S1 All the accepted fitting results from $\mathrm{H} 3$, coded by the color of the curves. 

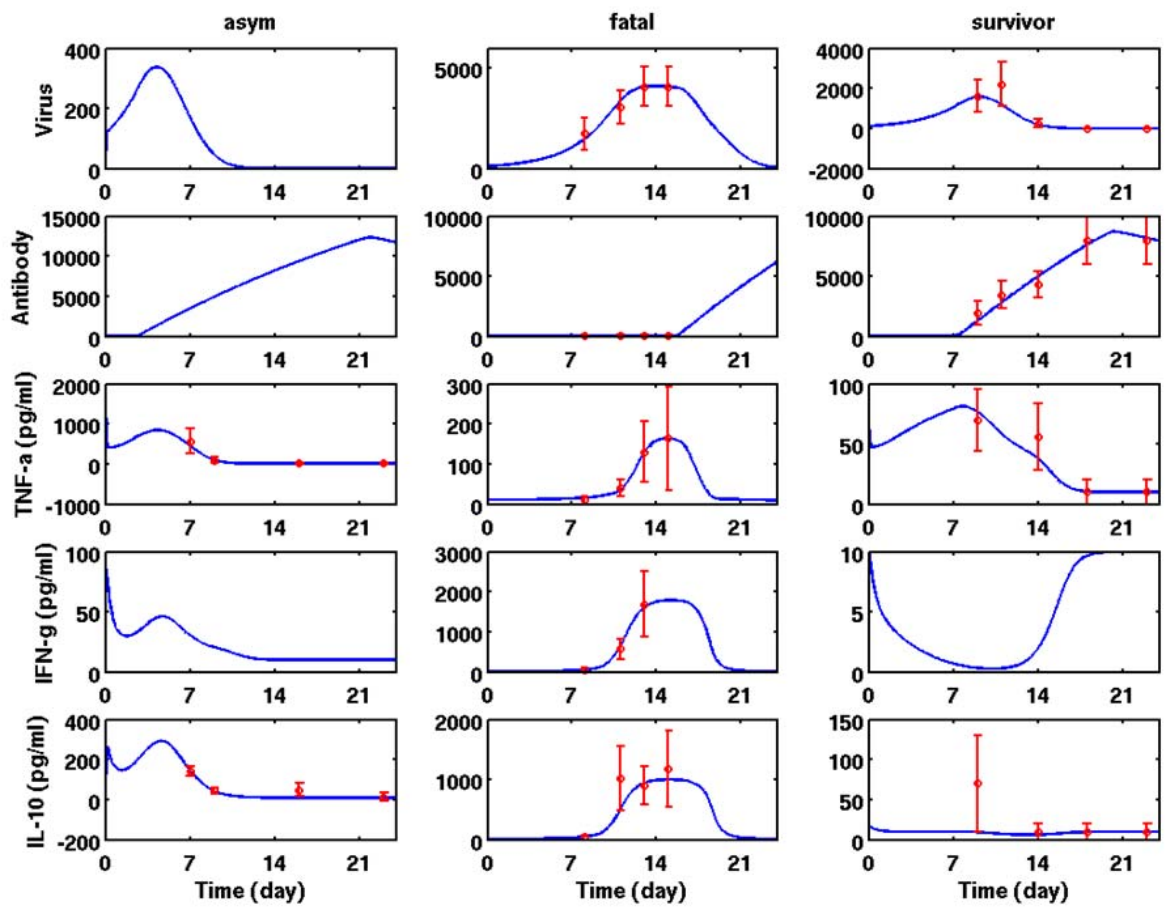

129

Fig. S2 The best fitting results from $\mathrm{H} 5$ 
Fig. S3
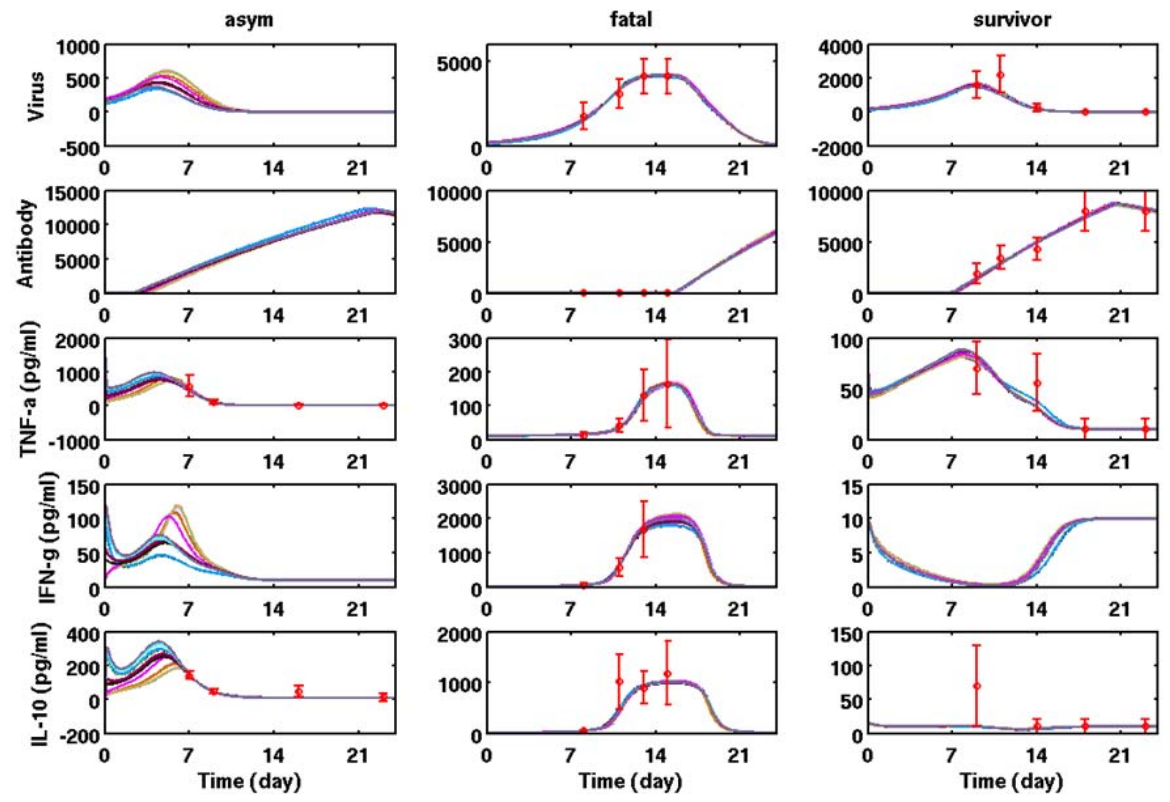

132

133

Fig. S3 All the accepted fitting results from $\mathrm{H} 5$, coded by the color of the curves. 


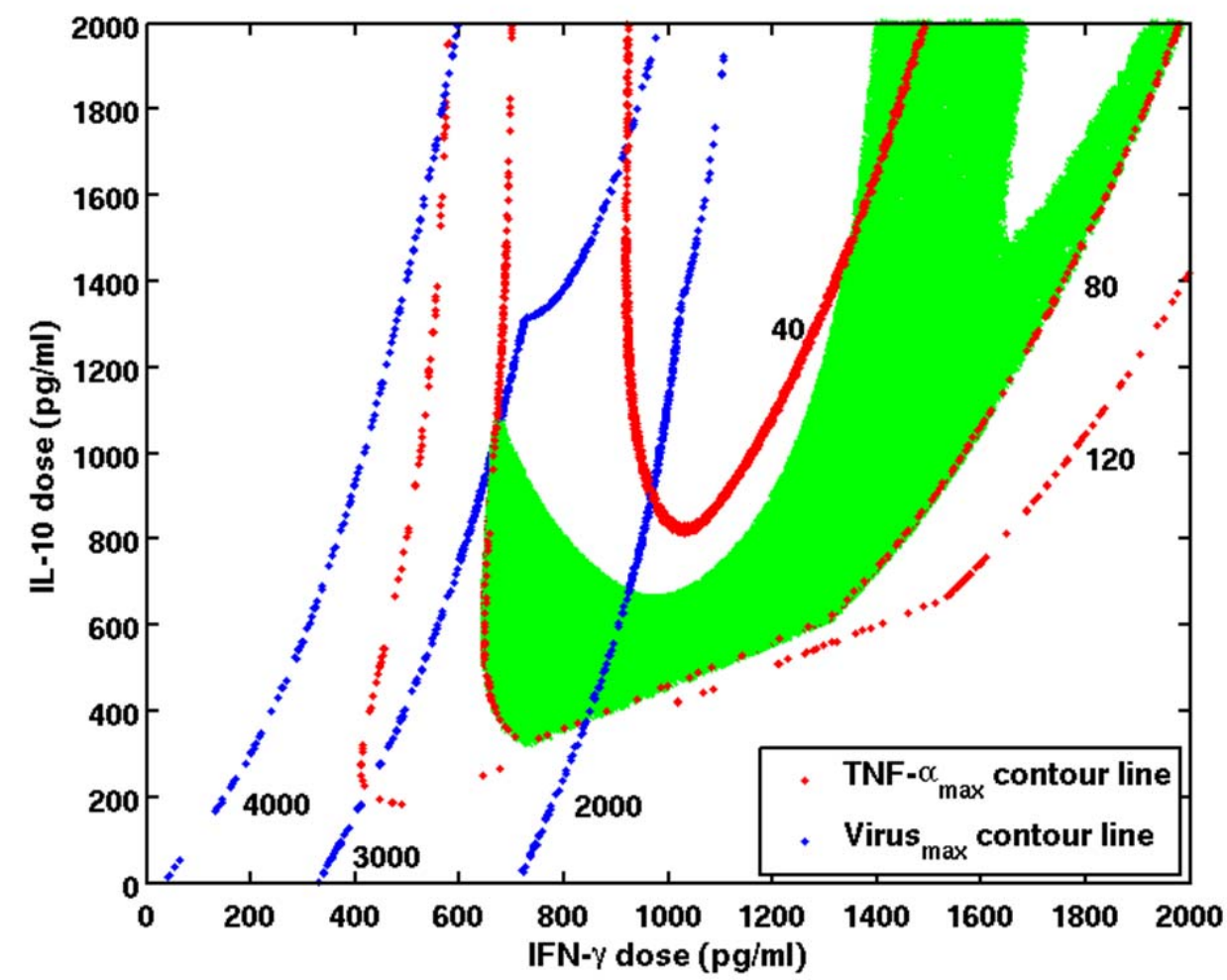

Fig. S4 The effect of the immune-interfering therapy depends on the dose of exogenous cytokines.

Three contour lines of the maximal viral load (blue) and the maximal TNF- $\alpha$ level (red) during the

therapy are plotted. The region is marked green (i.e. successful) if 1) the maximal TNF- $\alpha$ level 


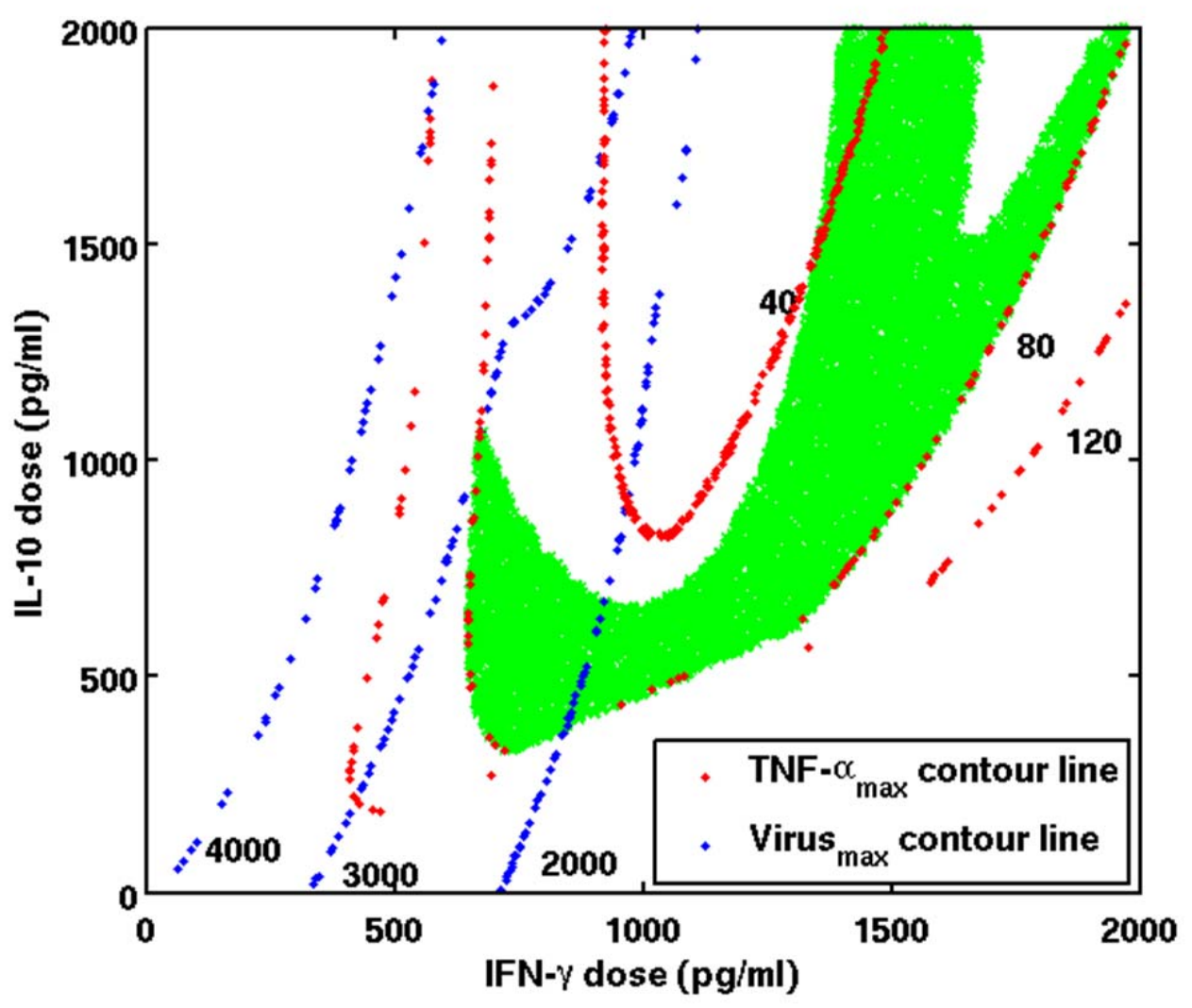

Fig. S5. Same as Fig. S4, except that model parameters are based on the best fit from H5. 
